\title{
La organización de las acepciones en un diccionario histórico
}

\author{
Rafael García Pérez \\ Universidad Carlos III de Madrid
}

\section{INTRODUCCIÓN}

Si la redacción de las definiciones es una tarea compleja en toda obra lexicográfica, en el caso de un diccionario histórico resulta especialmente delicada. Al contrario de lo que sucede en los diccionarios sincrónicos, donde el lexicógrafo cuenta con fuentes de información y corpus numerosos y de muy diversa índole, en los diccionarios diacrónicos la selección del material, sobre todo los datos reales acerca del uso de los vocablos, es mucho más restringida. En general, se puede decir que disponemos únicamente de fuentes documentales, que son tanto menos numerosas cuanto más retrocedemos hacia los orígenes de nuestra lengua. Esto, evidentemente, tiene repercusiones en el modo con el que el lexicógrafo se acerca a los datos y trata de organizarlos, y resulta explicable, en estas condiciones, la tentación filológica de agrupar y definir las voces contextualmente, dando fe de un exhaustivo trabajo de interpretación de los textos. No es de extrañar, por tanto, que el Diccionario Histórico elaborado por la Real Academia Española (en adelante $D H$ ) haya optado, precisamente, por su orientación filológica, reflejada en la minuciosidad con que se presentan los datos. Nos hallamos ante un excelente fichero que ordena con exactitud la realidad lingüística reflejada en los textos.

En ese sentido, el trabajo realizado por los académicos es irreprochable. Se adecua perfectamente a un modelo lexicográfico que aspiraba a ordenar del modo más escrupuloso un amplio fichero, previamente contrastado con las mejores ediciones, pero que no contaba con los recur- 
sos propuestos por las nuevas tecnologías. En la actualidad, sin embargo, los avances en el campo de la informática han provocado, también, cambios importantes en la teoría lingüística y en la concepción de la técnica lexicográfica. Los ordenadores nos permiten, por primera vez, establecer un sistema de relaciones internas entre las diversas partes del diccionario, capaces de explicar adecuadamente los cambios semánticos. Si en algo tenían razón los estructuralistas era, precisamente, en el hecho de que las unidades lingüísticas no están aisladas, y que las alteraciones a las que pueden verse sometidas en un momento concreto provocan, a su vez, la transformación de otras unidades del sistema. La concepción del diccionario como obra relacional, donde los valores de los vocablos se explican por contraste con los valores de sus sinónimos y antónimos e incluso los miembros de su misma familia morfológica, supone tomar decisiones arriesgadas ${ }^{1}$. Desde el punto de vista de la definición, tema que nos ocupa aquí, una vez determinados los casos particulares en que se usa un vocablo y destacadas las palabras concretas que selecciona, hay que recurrir a modelos que permitan relacionar sus significados y acepciones y éstos con las de otras palabras. Se trata de establecer, por encima del detalle contextual, los semas básicos, planteando, al mismo tiempo, las direcciones en las que se han ido produciendo los cambios. De este modo, obtendremos no sólo una imagen más precisa del pasado de nuestra lengua, sino también una explicación más racional de los fenómenos léxicos contemporáneos considerados residuales por los estudios puramente sincrónicos.

Este artículo forma parte, pues, de un proyecto dirigido a plantear la necesidad de valorar los hechos relacionales en la elaboración de un diccionario histórico. Ya en otra publicación se ha abordado, tomando el ejemplo de la entrada antojar ${ }^{2}$, el estudio de las conexiones genéticas entre los vocablos, como una más de las posibilidades de relación que han de tenerse en cuenta. Más allá de ellas, el presente trabajo revelará

1 En lo que respecta a la macroestructura, por ejemplo, habrá que superar la clasificación por orden alfabético, que tanto predicamento ha tenido entre los lexicógrafos tradicionales. Se trata de un asunto demasiado extenso para tratarlo en estas páginas.

2 Pascual y García Pérez (en prensa). 
cómo los hechos relacionales pueden contribuir, incluso, al establecimiento de las acepciones en los artículos de un diccionario.

Aprovechando la buena labor de la obra académica, que parte de una hipótesis no relacional, pero bien fundada, pretendo diseñar, a continuación, un modelo de organización del significado, en general, y de las acepciones, en particular, más acorde con las posibilidades de las nuevas técnicas lexicográficas. Lo voy a ejemplificar con la entrada aderezar.

\section{LA PRESENTACIÓN DE LOS DATOS EN EL DH}

El $D H$ divide sus artículos en ramas semánticas generales, acepciones y subacepciones ${ }^{3}$. Las primeras aparecen numeradas con cifras romanas; las segundas, con números arábigos; y las terceras, con letras $-a), b$ ), etc.- siguiendo un esquema tradicional en el que las subacepciones se consideran extensiones de la acepción bajo la cual se disponen y las acepciones, a su vez, extensiones particulares de la rama general. Cada una de ellas aparece ejemplificada con fragmentos de textos ordenados según su antigüedad. En el caso de la entrada aderezar, nos encontramos con un total de 29 acepciones agrupadas en seis ramas semánticas.

Para mostrar mejor los criterios determinantes que han regido la definición del artículo, haré un breve recorrido por él desde lo particular a lo general. Empezaré, por tanto, por exponer los rasgos propios de las subacepciones.

\subsection{LAS SUBACEPCIONES}

1.1.1. Constituyen el ejemplo más claro de la voluntad taxonómica con que se ha elaborado el diccionario, por lo que suponen de intento de poner un orden en la masa de ejemplos que se han extraído previamente de los textos. Si nos fijamos en la acepción número 12 (arreglar, recomponer, reparar cosas materiales) comprobaremos que su división en subacepciones tiene mucho que ver con el deseo de organizar de al-

3 El término rama procede de Seco (1987: 74 y ss.). 
gún modo los sustantivos concretos con los que suele combinarse. Así, en b) aparecen los diversos ejemplos en que aderezar, con el sentido de 'reparar', rige sustantivos referidos a algún tipo de embarcación, mientras en e) rige a sustantivos relacionados con las armas.

b) tr. Reparar embarcaciones. Ú. t. en sent. Fig. [...] 1541-42 CARVAJAL, FR. GASPAR Descubr. Río Amazonas (1894) 78: Aquí pusimos por obra de aderezar el bergantín pequeño de manera que pudiese navegar.

e) tr. Recomponer, arreglar armas. $\mathbf{c 1 5 6 8}$ DÍAZ DEL CASTILLO Hist. NEspaña (1940) 119a: Estando en nuestro real [...] entendiendo en adereçar armas y en hazer saetas y cada uno en lo que avía de menester para en cosas de guerra [...] vino uno de nuestros corredores de campo.

El verbo aderezar aparece, en estos ejemplos, en su sentido de 'arreglar', combinado, entre otros sustantivos, con tipos de barcos y armas; pero no se aporta ninguna información nueva de carácter semántico digna de interés para el usuario. De hecho, parece evidente que la exhaustividad en la presentación de estos conjuntos léxicos tiene mucho que ver con la frecuencia con que las combinaciones verbo-complemento se hallan registradas en el corpus textual. El lexicógrafo se ha dado cuenta de que ciertos sustantivos pueden agruparse en clases, $\mathrm{y}$ eso le permite ordenar los datos de un modo coherente y homogéneo. El problema que se plantea, sin duda, es que las clases léxicas pueden resultar más o menos abiertas ${ }^{4}$. Con un número menor de ejemplos, llegan a resultar casi un cajón de sastre:

c) tr. Arreglar, reparar, limpiar un camino, un paso, un puente, etc. 1522 HERNÁN CORTÉS Cartas (1866) 199: No me partí de allí fasta que todos aquellos pasos malos quedaron muy bien aderezados.

4 Hasta tal punto que, según el volumen de ocurrencias, se puede alterar la clasificación en otros artículos con acepciones idénticas. La acepción número 9 de la entrada aderezar, definida como "componer, arreglar el cuerpo o el rostro con cosméticos, perfumes etc." presenta una subacepción en la que se señalan los casos en los que el verbo se combina con sustantivos referidos a partes concretas del cuerpo: "b) Peinar, arreglar el cabello, las cejas, el bigote, etc. Ú. t. c. prnl" La entrada acicalar no hace distinciones entre el cuerpo en general y sus partes. Su acepción número 5 recoge indistintamente ejemplos referidos a ambos grupos. 
f) tr. Arreglar, componer, reparar casas, tejados, etc. 1573-82 SANTA TERESA Fundaciones $\mathrm{f}^{\circ}$ 8: Esta casa estava tan sin paredes, que a esta causa alquilamos estotra, mjentra que aquélla se adereçava.

Precisamente, el intento de distinguir con tanta precisión entre clases de sustantivos puede traicionar al lexicógrafo y revelar su carácter artificioso, como sucede en uno de los ejemplos integrados en c), claramente en conflicto con $\mathrm{f}$ ):

El oficio de gobernador, y en que se ocupa y ejercita, es lo siguiente: [...] hace aderezar los caminos y puentes y casas de cárcel y Audiencia, y las plazas y lugares comunes.

La coordinación de sustantivos tan dispares en función de complemento es, sin duda, una muestra de la escasa pertinencia lingüística y lexicográfica de estas clasificaciones ${ }^{5}$.

5 Dentro del mismo artículo, las acepciones número 6, 9, 21 y 23 presentan problemas parecidos. El procedimiento se extiende por todo el diccionario. Cito, sólo a título indicativo, algunos otros artículos de la letra A en que las clasificaciones resultan excesivamente restringidas: la acepción número 2 de aparasolado se divide en las dos subacepciones siguientes: "En botánica: umbelíferas. [...] 1815 LA GASCA (Colmeiro, Bot. y botánicos 1858, 193a): Disertación sobre la familia natural de las aparasoladas. [...] b) Perteneciente a la familia de las aparasoladas o umbelíferas. Dicho de planta. [...] 1825 LA GASCA (Colmeiro Bot. y botánicos 1858, 194a) Observaciones sobre la familia natural de las plantas aparasoladas"; la acepción número 3 (propio o característico del parasol) distingue, por su parte, entre las combinaciones "forma aparasolada" y "cosa aparasolada": "3 Propio o característico del parasol. Dicho de forma. 1866 OLIVÁN Agric. 183: Consiste la poda [...] en redondear el ramaje del árbol a lo exterior, con ramillas colgantes que den al árbol forma aparasolada. [...] b) De forma semejante a la del parasol. Dicho de cosa y especialmente de árboles y sus copas. [...] 1962 ACOSTA SOLÍS. Flores de tierra ambateña, 25: El "guarango" (Tara spinosa) es un árbol aparasolado y floral digno representante de las tierras secas y arenosas". La acepción número 9 de aparejar presenta dos subacepciones particularmente minuciosas: "9. tr. Adornar o aderezar (a alguien o algo) 1330-35 JMANUEL Lucanor (1983) 100, 79: Dende a cabo de siete o de ocho días, vinieron dos escuderos muy bien vestidos et muy bien aparejados. [...] b) tr. Vestir o ataviar (a alguien) normalmente con esmero. Gralm. el compl. dir. es refl. 1400 Lib. Maravillas (1979) 113b) Pues son todos aquéllos del parentesco del emperador apareillados muy noblement de paynnos d'oro". En el mismo artículo se encuentran otros ejemplos; sin pretender ser exhaustivo, remito al lector a las acepciones 8, 13 y 19. La entrada acicate contiene una acepción (número 3) que se define como "espuela provista de acicate", la cual se 
1.1.2. Un problema íntimamente ligado a éste y, en principio, difícil de detectar -hasta tal punto que puede tender trampas insospechadas incluso a los propios lexicógrafos- es el que afecta a la relación abusiva que se establece entre el significado de los vocablos y la metalengua utilizada en la definición. La separación de acepciones y subacepciones obedece, en muchos momentos, a la proyección inconsciente de la estructura lingüística del español actual en la lengua del pasado. En realidad, se define desde la perspectiva del diccionario actual, lo que supone ocultar la complejidad de los antiguos usos y la importancia de los cambios. Poniendo en relación las combinaciones léxicas extraídas del corpus textual con supuestos equivalentes de la lengua actual se tiende a interpretar contextualmente el verbo y a dar una imagen alejada de la evolución real en el tiempo ${ }^{6}$. Así, la distinción de la subacepción 6 b) se basa en la sinonimia entre el significado de aderezar (arreglar) y amortajar cuando acompaña a sustantivos relacionados con cadáveres:

6. tr. Arreglar, adornar con vestidos, joyas, etc; ataviar.

b) Amortajar, arreglar y componer un cadáver

[...] 1550 SEPÚLVEDA, L. Romance (BibAE, X) 436 b: Al conde muerto le hallaban, / En baños al conde meten, / Su persona aderezaban

Es frecuente, precisamente, que se justifique la separación de subacepciones con una larga enumeración de sinónimos del español actual, desde los más amplios a los más restringidos, que hacen imposible, al

divide en dos subacepciones; la primera correspondería al sentido recto y la segunda, al sentido figurado: "b) Úsase también en sentido figurado. 1615-1621 CÉSPEDES Y MENESES Español Gerardo (1623) $161 v^{\circ}$ : Yo, que horas antes estaua en vela, con azicates los oídos y el sentido alerta, oí que atrauessaban por delante de las puertas de mi aposento algunas personas". Esta subacepción precede a la acepción número 4, definida como "En sentido figurado, incitación, impulso, empuje; aliciente, estímulo. [...] 1624-30: LOPE DE VEGA Por la puente II(1930) 256 b): Quita al halcón las pihuelas / será del viento acicate; / que de palomas fregonas / he visto una banda alli'". Véase también la entrada adepto, en sus acepciones $2 \mathrm{~b}$ ) y 3 . Los casos son, por lo tanto, abundantísimos y ponen de manifiesto una voluntad tácita de los lexicógrafos de clasificar las entradas según las palabras con las que contextualmente se combinan.

6 Esta idea relativa a la metalengua de la definición, para la que se toman ejemplos de subacepciones, es también aplicable, con todo rigor, a las acepciones, como tendrá ocasión de comprobarse más adelante. 
tomarlos como base de sustitución, el intercambio de unidades de uno a otro grupo:

12. Arreglar, recomponer, reparar cosas materiales.

d) tr. Recomponer, remendar, arreglar, coser ropas.

El apartado 12 d) quedaría así respaldado y se opondría, por ejemplo, al 12 e), definido como "recomponer, arreglar armas". Sin embargo, en ambos casos, la sinonimia es engañosa. Aderezar, como arreglar en la actualidad, no significaba propiamente coser ni remendar, aunque en algunos contextos pueda interpretarse como tal. En muchos de los ejemplos, ni siquiera sabemos por qué equivalente (si no es arreglar) deberíamos "traducir" el verbo.

1554 RDGZ FLORIÁN, J. Florines (NBAE XIV) 239 a: Ay, madre, no llores más, y adereça esos atuendos de tocados. 1608 Balbuena Siglo de Oro 56v ${ }^{\circ}$ : Tu desasosiego nace de amor [...] Peyna tu cabellera, adereça tu pellico, labra vn buen cayado, remienda tus abarcas, [...] muéstrate regocijado y placentero.

Además, desde el punto de vista histórico, estas clases léxicas delimitadas por sinónimos de la lengua actual no tienen especial carácter representativo, pues evolucionan en la misma línea que la acepción en la que se incluyen. Como veremos, el verbo aderezar, en el sentido de la acepción 6, fue sustituido por "arreglar" sin dejar rastro de combinaciones con clases como la ropa o las armas (al contrario de lo que sucede con otros campos, como la cocina, donde la sustitución de aderezar por los verbos arreglar o preparar no ha impedido la conservación de ciertos restos lingüísticos, como la expresión "aderezar la ensalada"). Un diccionario histórico, por tanto, sólo debería tomar en consideración, como subacepciones basadas en combinaciones léxicas, clases muy específicas que ofrezcan una explicación de las particularidades evolutivas de las palabras. Evidentemente, eso significa conocer también, desde la perspectiva de su transformación históri$\mathrm{ca}$, todos los vocablos que, de uno u otro modo, interfieren con ellas en cada caso, bien sustituyéndolas, bien provocando ajustes semánticos de diverso tipo. Este estudio no puede hacerse tomando las palabras como unidades independientes, sino desde la perspectiva de un método relacional exhaustivo. 
1.1.3. A veces, la distinción de subacepciones en el $D H$ se apoya en una detallada delimitación del "sentido figurado" de los lemas. Sabemos que, según la práctica lexicográfica tradicional, todo sentido figurado que haya sufrido un proceso acusado de lexicalización y, consecuentemente, establezca un nuevo significado da lugar a una acepción o subacepción independiente ${ }^{7}$. El intento de determinar el uso metafórico de los vocablos en los diversos contextos en que éstos aparecen es tarea complicada; aquí también es necesario hilar muy fino para no confundir el empleo de la palabra que se trata de definir con el resto de las unidades lingüísticas que la rodean. En el $D H$, el rigor con que se ha pretendido mostrar las pequeñas variantes metafóricas del verbo aderezar ha conducido, en ocasiones, a clasificar impropiamente ciertos empleos "rectos" como subacepciones "figuradas"; el apartado b) de la acepción 17 , por ejemplo, recoge simples usos metafóricos de sustantivos regidos por el verbo, pero no variantes de significado de aderezar.

b) Ú. t. en sent. fig.

1565 GRANADA. Mem. Vida cristiana (1907) 145: Para necesitados se dio este socorro, y para hambrientos se aderezó este manjar [de la comunión] 1861 CAMPOAMOR Polémicas (1901) 431: Yo no extraño que algunos economistas me critiquen por mis opiniones $[\ldots]$ Los señores marmitones de la casa del Estado me lo perdonarán, pero [...] por más bien que aderecen sus compotas, siempre serán unos señores marmitones.

Lo mismo puede decirse del apartado b) de la acepción 18 .

b) Ú. t. en sent. fig.

1585 CUEVA, J. Viage Sannio (1887) 50: Huyendo la sartén, das en el fuego / ipobre poeta! porque se adereza / un guisado, a tu gusto tan sin gusto / i cual a ti, por ser Poeta, justo.

Es evidente que la utilización de los sentidos figurados en un $D H$ debe analizar con mucha precaución la relación entre el alcance metafóri-

7 La consideración como acepción o subacepción depende de la cercanía o lejanía del "sentido figurado" al "sentido recto". En general, los estudios metalexicográficos, al tratar de la microestructura, no mencionan criterios diferenciadores y se deja al arbitrio de los lexicógrafos la decisión de clasificar entre las acepciones o subacepciones el uso metafórico normalizado. 


\section{co de un párrafo o un texto y el significado concreto de las unidades que lo constituyen.}

\subsection{LAS ACEPCIONES}

Las acepciones tratan de distinguir diversos sentidos dentro del hilo conductor que constituye la rama semántica general. Sabemos que la separación entre ellas y su redacción es una tarea difícil sobre la que la lexicografía no ha establecido criterios únicos e indiscutibles ${ }^{8}$. Depende

8 El concepto de acepción se define vagamente haciendo referencia a los sentidos fijados por el uso. Casares señala que "Cada uno de estos sentidos especiales o generales es lo que en lexicografía constituye una acepción" (1992: 58). Y más adelante predica un "in medio virtus" bastante ambiguo cuando habla del número de acepciones que es posible establecer: "Cuál de estos criterios extremos sea preferible es cosa que no puede decidirse con argumentos y que depende en gran medida del material con que se trabaja y de la concepción personal de los redactores. Desde luego hay que convenir en que la bifurcación en ramas, ramos y ramitos, llevada hasta el último extremo, perjudica notablemente la perspectiva de conjunto, aunque contribuya, por otra parte, a explicar la genealogía de cada una de las acepciones. La excesiva condensación, en cambio, tiene el inconveniente, sobre todo para un diccionario con citas, de que obliga a prescindir de muchas de ellas, a veces preciosas, so pena de juntarlas promiscuamente con mengua de su eficacia ilustrativa, a más de que no permite observar la fase en que se halla el proceso de especialización de las acepciones recientes" (1992: 5859). Porto Dapena, sin negar el carácter un tanto subjetivo de esta operación, hace un resumen de los principales criterios que, con mayor o menor fortuna, se han venido señalando para lograr una separación de acepciones más coherente. Por un lado, hace alusión a las grandes distinciones según criterios de homonimia, valor categorial, diasistema y usos rectos y figurados, que resultan poco problemáticos y han sido utilizados, en la práctica, por la lexicografía tradicional. Por otro, se refiere expresamente a las unidades polisémicas, para las que establece criterios léxico-semánticos de separación de acepciones, basándose en autores como Melčuk o Coseriu: los criterios de interpretación múltiple, de diferencia semántica local frente a diferencia semántica global, de coocurrencia compatible, de coocurrencia diferencial y de derivación diferencial deben mucho a la distinción difundida por el primero entre ambigüedad y vaguedad, según la cual sólo podría hablarse de acepciones diferentes en los casos en que un vocablo resulte claramente ambiguo en el contexto y no meramente vago; otros criterios, como los de sinonimia, oposición, y designación aparecen como complementarios; un último criterio recogido en esta obra es el criterio de valencias o argumentos actanciales, que parte de las diferencias de construcción semántico-sintáctica (2002: 203-224). 
mucho, en ese sentido, del punto de vista del lexicógrafo, aunque también de los criterios complementarios, morfológicos o sintácticos que puedan contribuir a llevar a cabo esta labor con cierta coherencia y fiabilidad. Las diversas construcciones formales en las que el verbo aderezar se presenta en los ejemplos de las acepciones 3 y 5 son significativas:

3. intr. Dirigirse, encaminarse a un sitio determinado. Ú.t.c.prnl. [...] 1330-35 J MANUEL Lucanor (1900) 46, 16: Adereçó luego a casa de don Yllán et fallólo que estava leyendo.

5. tr. Dirigir, enviar, dedicar (palabras, cartas, escritos, etc).

Ú.t.c.pronl. 1400? Quatro Dotores (1897) 107,2: Agora aderesçeré toda mi oraçión a ti.

Es evidente que los dos sentidos están bien diferenciados, tanto semántica como sintácticamente, y las dos acepciones, por tanto, justificadas. En el primer caso nos encontramos con un verbo intransitivo de dirección que selecciona un complemento locativo; en el segundo, con un verbo transitivo que selecciona dos complementos, uno de cosa-objeto directo- $\mathrm{y}$ otro de persona -objeto indirecto.

Más complicado resulta justificar sentidos distintos partiendo de una misma estructura sintáctica a la que pueden atribuirse varios sujetos o complementos potenciales. Se trata de utilizar una técnica lexicográfica consistente en especificar en el texto definitorio el elemento de la realidad implicado en la acción ${ }^{9}$. Así en la definición actual de aderezar que propone el $D R A E$, la cuarta acepción incluye una referencia al tipo de ente (aquí, cosa) al que se aplica el verbo:

4. Remendar o componer alguna cosa.

El $D H$, inspirándose también en esta técnica, tiende a multiplicar el número de acepciones diferenciando, explícita o implícitamente, entre aquellos seres (persona o grupo humano, animal en general o especie del mundo animal, cosa, etc.) capaces de desempeñar las funciones sin-

9 La toma de conciencia de que la especificación de dicho elemento, que concretaba, en muchos casos, los usos reales del vocablo y enriquecía la definición, no cumplía la ley de la sinonimia al formar parte integrante de la definición dio lugar, hace algunos años, a la teoría lexicográfica del contorno (Seco 1987: 15-45). 
tácticas relacionadas con la palabra definida. Así, las acepciones incluidas en la rama semántica II (idea general de adornar, hermosear, embellecer) de la entrada aderezar tienen su razón de ser en la aplicación de este significado a varios elementos de la realidad que actúan como complemento directo del verbo: personas, cuerpos o partes del cuerpo, lugares, objetos, caballerías, y obras y acciones en abstracto.

6. tr. Arreglar, adornar con vestidos, joyas, etc.; ataviar.

7. Adornar, decorar, amueblar un aposento, una casa, una calle o un lugar en general.

8. Adornar, decorar un objeto.

9. Componer, arreglar el cuerpo o el rostro con cosméticos, perfumes, etc.; acicalar. Ú.t.c.prnl.

10. Enjaezar una caballería.

11. Acompañar, complementar una acción, una obra, etc., con algo que le añade gracia o adorno, énfasis; destacarla.

Esta multiplicación de las acepciones, al contrario de lo que sucede en otros diccionarios, tiene más que ver con la voluntad filológica de clasificar y presentar ordenadamente el gran número de ocurrencias aparecidas en el corpus textual que con la definición del significado; de ahí que me haya referido a la condición de fichero cuidadosamente ordenado. Es evidente que la distinción entre acepciones puede llevarse a extremos innecesarios cuando se atomizan los contextos y se deducen los sentidos de meras variantes creadas por el entorno léxico de la palabra. Todo sentido general puede teñirse de matices, puesto que se aplica, en el uso cotidiano, a numerosas realidades concretas, pero su coloración contextual no debería conducir al establecimiento de acepciones cuya existencia llegara a revelarse un tanto artificial. El primer ejemplo de la acepción número 9 pone de manifiesto cómo aderezar recibe una interpretación más limitada debido a su inclusión en un discurso orientado por palabras pertenecientes al campo semántico del arreglo físico, pero no nos presenta ninguna particularidad semántica:

9. tr. Componer, arreglar el cuerpo o el rostro, con cosméticos, perfumes, etc.; acicalar. Ú.t.c.prnl.

1534 BOSCÁN Trad. Cortesano Castiglione (1540) 27 vo: Estraño deseo tienen generalmente todas las mugeres de ser o a lo menos de parecer hermosas [...]; de aquí nace el afeytarse, el ponerse mil azei- 
tes en el rostro, el enruuiarse los cabellos, el hazer se las cejas y pelarse la frente y el padecer otros muchos tormentos por aderezarse.

Lo mismo puede decirse de la acepción número 6, donde la restricción procede de la orientación del discurso o de algunos complementos preposicionales regidos por el verbo cuyos sustantivos se refieren al vestido $^{10}$ :

6. Arreglar, adornar con vestidos, joyas, etc.; ataviar. Ú.t.c.prnl.

1251 Calila (ms s.XV ed. 1906) 151-251: Orfate, cuando sopo que el rrey estaua con Helbeld, ouo ende çelos et vestióse aquellos vestidos, e adereçóse lo mejor que pudo, et entró en la cámara donde estaua el rrey con Helbeld.

[...] 1613 CERVANTES Señora Cornelia 229 vo: Se aderece esse niño muy bien, y ponedle, señora, las joyas todas que tuuiéredes.

[...] 1530 CoDo In Amér. Ocean XIII (1870) 389: Algunos indios que se tomaron $[\ldots]$ benían bien aderezados de mantas y plumajes, y muy lindos carcajes de flechas muy labradas.

La atomización puede hacer complicada la clasificación si el contexto no proporciona al lexicógrafo las suficientes señales orientativas. Los dos ejemplos siguientes, tomados de las acepciones 6 y 9 respectivamente, casi podrían ser intercambiables:

1523 GUEVARA Epist. (1595) 167: Los viejos de vuestra edad tienen obligación de andar muy limpios y bien aderezados.

1880 ALARCÓN, P. A. Niño Bola 226: Mozas aderezadas y carilimpias.

De hecho, la distinción entre ambos ejemplos parte, más bien, de una suposición: la diferencia de sexos a los que se refiere el sustantivo. Respecto a los viejos (varones), se presume que no se utilizan afeites; respecto a las mozas (mujeres), se supone que solían aplicar afeites al rostro.

10 El hecho de que se trate de un objeto y no de una persona lleva a distinguir entre estos complementos referidos al vestido y los referidos a otras telas o materiales, incluidos en otra acepción: "8. Adornar, decorar un objeto. [...] 1607 J DE LOS ÁNGELES Consider. Cant. Salomón (NBAE XXIV) 314a) Mi lecho tengo tejido y enlazado de cordeles $[\ldots]$ colgado y aderezado de tapicería de Egipto. 
La excesiva especialización contextual, por otro lado, puede hacer confusa la separación entre acepciones y subacepciones. Las acepciones número 7 y número 8 son difíciles de justificar teniendo en cuenta lo visto acerca de las subacepciones:

7. Adornar, decorar, amueblar un aposento, una casa, una calle o un lugar en general. Ú.t.c.prnl. y en sent. fig.

[...] 1633 CARDUCHO Diál. Pintura (1865) 343: Las bóvedas [...] están aderezadas con muchas pinturas.

8. Adornar, decorar un objeto.

[...] 1559 MONTEMAYOR J. Diana (1955) 123: El mi don Felis traía calças de terciopelo blanco recamadas [...], espada, daga y talabarte de oro; una gorra muy bien aderezada de unas estrellas de oro.

En el mismo $D H$ se menciona la dificultad de adscribir ciertos ejemplos a una u otra acepción cuando éstas se basan en clasificaciones léxicas demasiado cerradas:

17. Preparar o disponer comida. Ú.t.c.intr.

Muchos de los ejs. de esta acep. pueden referirse a la acep. 18, pero por no especificarse se dejan en ésta, más general.

18. Guisar, preparar los manjares, sometíéndolos a la acción del fuego.

La distinción procede, por tanto, de una orientación contextual en la que "preparar" se entienda únicamente como "guisar". Evidentemente, y puesto que sólo contamos con el corpus de textos escritos, el determinar tal acepción, muy cercana desde el punto de vista semántico a la precedente, resulta complejo.

1834 LARRA El doncel (1843 I) 151: Salieron de la selva dos ginetes galopando a más galopar hacia las tiendas donde se aderezaba el banquete para la noche.

La preocupación por las mínimas variaciones contextuales puede llevar, incluso, a contradicciones indeseadas, como sucede con la acepción 21, cuya subacepción c) no es más que una continuación de la acepción $7^{11}$ :

21. c) Preparar, disponer, arreglar un cuarto, aposento, casa, etc.; amueblarlos, limpiarlos. Ú.t.c.abs. Úsase especialmente en la expresión aderezar posada.

11 Lo mismo puede decirse de la acepción 17 y la 21h). 


\subsection{LAS RAMAS SEMÁNTICAS}

El concepto de rama semántica, como una especie de macroacepción que engloba en una unidad semántica más amplia a diversas acepciones, ha sido poco utilizado por la técnica lexicográfica. La mayoría de los diccionarios se limitan a recoger acepciones y subacepciones en un número variado, pero no tratan de clasificarlas en una unidad semántica de más amplio alcance. Las ramas semánticas se establecieron en el $D H$ como un mecanismo más de agrupamiento, tratando de dar coherencia a los múltiples sentidos que parecían desprenderse de las entradas. El término, definido propiamente por Manuel $\mathrm{Seco}^{12}$, lo tenían en mente los redactores desde hacía tiempo. Fue Julio Casares el que lo introdujo, sirviéndose de una metáfora arbórea en la que se presenta el significado de la palabra como una raíz que se hunde en la tierra madre (el latín) y se ramifica en acepciones y subacepciones más o menos alejadas del origen (1992: 71 y ss.). Si, en un principio, la intención era que las grandes ramas semánticas (o series) recogieran los sentidos básicos y establecieran el punto de contacto entre el significado original y su evolución en castellano, creando una definición diacrónica ideal, lo cierto es que las circunstancias y las condiciones particulares de cada palabra complican enormemente la tarea. Es frecuente que las ramas terminen convirtiéndose en meras superacepciones ordenadoras, al margen de la base etimológica de la entrada. Esto es lo que sucede en el caso de aderezar, cuya definición se divide en seis grandes ramas, con un "hilo conductor" que pretende dar una idea general de las acepciones englobadas en cada una de ellas. La metalengua utilizada, en ese sentido, resulta significativa:

I. Con idea general de guiar, dirigir, encaminar.

II. Con idea general de adornar, hermosear, embellecer.

III. Con idea general de arreglar.

La última rama semántica constituye una especie de cajón de sastre que incluye frases proverbiales usadas, preferentemente, en el s. XVII. La creación de una rama semántica específica centrada en la recopila-

12 Véase nota 3. 
ción de fraseología confirma una vez más el carácter taxonómico de estos supergrupos.

Dejando al margen el problema que plantea equiparar la rama VI a las precedentes ${ }^{13}$, no estaría de más señalar que las "ideas generales", tal y como están definidas, pueden resultar excesivamente confusas por minuciosas. En ese sentido, las ramas II, IV y V, por ejemplo, separan supuestos significados genéricos que se hallan, o bien en intersección, o bien delimitados contextualmente. Así, la idea de "preparar" (de la acepción V) y la de "hermosear" (de la acepción II) entran en contacto y resultan más que difíciles de distinguir en ejemplos como el siguiente, ya señalado anteriormente, pero que conviene ampliar por sus especiales repercusiones en la consideración de las ramas semánticas:

II. Con idea general de adornar, hermosear, embellecer.

[...] 7. tr. Adornar, decorar, amueblar un aposento, una casa, una calle o un lugar en general. [...] 1458-71 Hechos Lucas Iranzo (1940) 35,22: Y por aquel dicho caballero embaxador avía de yr a dormir aquella noche a la Venta de los Palaçios, [...] el señor Condestable mandó $[\ldots]$ aderezasen muy bien la dicha venta, $[\ldots]$ e la yglesia de Santa Cruz, que está cerca della, donde otro día oyese misa.

V. Con idea general de preparar, disponer.

[... 21 c) tr. Preparar, disponer, arreglar un cuarto, aposento, casa, etc, amueblarlos, limpiarlos. Ú.t.c.abs. Úsase especialmente en la expresión aderezar posada. 1458-71 Hechos Lucas Iranzo (1940) 34: Aderezaron una buena posada [...] Todo aderesçado, salió el dicho Juanes a reçebir al dicho embaxador $[\ldots]$ y como llegó a la ora del medio día, y descaualgó, falló la posada muy bien adereseçada.

La misma metalengua utilizada en las acepciones y subacepciones revela que la diferencia entre "adornar amueblando" y "preparar amueblando" obedece más a razones extralingüísticas que puramente lingüísticas.

Las ramas semánticas IV y V son un ejemplo más de cómo la abundancia de los datos puede orientar la toma de decisiones a la hora de es-

13 Es una constante en toda la obra. Las expresiones fijas aparecen, normalmente, agrupadas bajo la numeración correspondiente a las ramas semánticas. 
tablecer los significados. La rama IV tiene más en común con cualquier acepción o subacepción que con el resto de las ramas, pues, curiosamente, se crea sólo para recoger todas aquellas combinaciones en las que el verbo rige sustantivos relacionados con la comida y la bebida, sin duda de los más numerosos del corpus. En ese sentido, puede aplicársele todo lo dicho acerca de las acepciones y subacepciones, aunque su situación en la microestructura del diccionario no sea la misma. La pretensión de convertir este conjunto de combinaciones léxicas en rama semántica viene forzada por la frecuencia de uso y su recategorización se resiente en la comparación con otras ramas menos arbitrarias, como la I, por ejemplo.

I. En acepciones relacionadas con la comida y bebida.

Por otro lado, su relación con la rama semántica V, donde la idea general de "preparar" se divide en acepciones constituidas por combinaciones léxicas particulares, es tan cercana que parece difícil justificar con firmeza la separación de ambas.

IV. En acepciones relacionadas con la comida y bebida.

17. Preparar o disponer comida. Ú.t.c.intr. [...]

18. tr. Guisar, preparar los manjares, sometiéndolos a la acción del fuego.

Etc.

V. Con idea general de preparar, disponer.

[...]

21. Preparar, disponer cosas materiales en general. Ú.t.c.abs.

Etc.

\section{HACIA UNA NUEVA DEFINICIÓN}

El $D H$ es, sin duda, un producto lexicográfico fundamental de la historia de nuestra lengua que responde perfectamente a la época en la que le tocó nacer ${ }^{14}$. Por las razones que he señalado anteriormente, sin em-

14 "Hemos visto experimentalmente que nuestro material, todavía incompleto, supera notablemente en información a los diccionarios franceses e italianos y hasta puede 
bargo, no se pudo establecer con comodidad relaciones entre las palabras. Fijémonos lo que supondría relacionar un grupo de ellas para trazar una línea histórica en la que se ponga de manifiesto cómo las unas se rozan con las otras. Parece evidente que un artículo como aderezar, tal y como aparece definido, no puede dar cuenta de por qué hoy decimos, por ejemplo, aderezar la ensalada y no aderezar una habitación, ni qué relaciones se establecen entre ese antiguo aderezar y los actuales preparar, arreglar, etc., que en tantos contextos han sustituido a aquél. La historia de las palabras es la historia del cambio semántico, es decir, la evolución de los significados por encima de la fijación de los usos lingüísticos accidentales de una época determinada. En ese sentido, la definición y organización de las acepciones debe concebirse de otra manera.

\subsection{LAS RAMAS SEMÁNTICAS}

El concepto de rama semántica, entendida como sentido genérico orientador de las acepciones concretas o "conceptos alusivos a la realidad" -variantes de uso, definidas, a su vez, desde un punto de vista puramente técnico- puede resultar de gran interés y, en consecuencia, conservarlas en el $D H$ es beneficioso. Evidentemente, deben responder a una idea general y, en ningún caso, confundirse con las acepciones o las subacepciones propiamente dichas. Las ramas semánticas no tienen que multiplicarse, porque aportan rasgos esenciales del significado. No dependen de contextos determinados, sino que constituyen abstracciones agrupadoras de conceptos relacionados.

Si estudiamos con detenimiento los ejemplos recogidos en la definición de la entrada aderezar, nos percataremos de que el número de ramas semánticas puede reducirse notablemente, con lo que la descripción lingüística no sale perjudicada, sino que gana en coherencia.

Tales ramas semánticas pueden limitarse a dos que, curiosamente, tienen su origen en la etimología latina del vocablo. Sin entrar en deta-

medirse sin desdoro con el formidable arsenal que sirvió de base al monumental Diccionario Oxford" (Casares 1992: 87-88). 
lles acerca de la precedencia cronológica de una u otra, aderezar procede del antiguo derezar, evolución fonética del latín vulgar *DERECTIARE, con el sentido de "dirigir" o "poner derecho" (DCECH, s. v. aderezar). Derectiare es, a su vez, un derivado de DiReCtus, participio de pasado de DIRIGERE ${ }^{15}$. La forma aderezar es posterior a enderezar, pero ambas son variantes de la primitiva forma derezar y conservan el sentido inicial. El significado global de la palabra sería algo así como "colocar rectamente, cambiar la situación o estado (con vistas a un objetivo)". No es de extrañar que una primera gran línea semántica pueda definirse como 'dirigir' y la otra como 'disponer adecuadamente'.

Con relación a las ramas semánticas del actual $D H$, se puede decir que se conserva, a grandes rasgos, la primera y se funden, por tanto, la segunda, tercera, cuarta y quinta. La sexta, por lo que he señalado más arriba, desaparece para dejar paso a un apartado especial dedicado a la fraseología. Tendré ocasión de ampliar la explicación sobre las líneas semánticas cuando presente la propuesta del nuevo artículo aderezar.

\subsection{LAS ACEPCIONES Y SUBACEPCIONES}

Con las acepciones y subacepciones tocamos uno de los campos más delicados de la definición en un $D H$. Si la acepción se define como cada uno de los sentidos de una palabra establecidos por el uso ${ }^{16}$, la delimitación de tales sentidos no puede llevarse a cabo sin contar con la parcelación conceptual del mundo que realizan los hablantes de una lengua en un momento histórico. Las acepciones son la representación de los conceptos. El hecho de que un vocablo determinado se utilice para designar varios elementos de la realidad diferentes es causa de su polisemia y, en ocasiones, de su ambigüedad en el discurso; aunque se trata de un hecho natural que, en todo caso, debe encargarse de resolver el

15 Verbo derivado de REGERE (conducir, guiar).

16 Las acepciones se corresponderían con la definición de los diversos sentidos de una palabra, entendiendo por sentido: "We shall take antagonism between readings as a defining criterion for the ambiguity of a linguistic expression. Where the ambiguous expression is a word, like bank or light, we shall say that it has more than one sense" (Cruse 2004: 106). 
diccionario, mostrando al usuario la relación entre la forma lingüística y el objeto conceptual al que se aplica, así como las relaciones con el resto de unidades del sistema ${ }^{17}$. Las subacepciones, por su parte, dependen estrechamente de las acepciones y sólo con relación a ellas pueden explicarse; son variantes contextuales relevantes que especifican o restringen los conceptos.

La separación de acepciones y subacepciones en el $D H$, como he señalado, sigue criterios de combinatoria léxica que no siempre tienen repercusiones conceptuales. En consecuencia, se puede considerar que su número se ha multiplicado innecesariamente por motivos de organización de datos más que por criterios semánticos.

Para que podamos hablar de acepciones y, por tanto, de sentidos diferentes es necesario que la palabra se presente como ambigua en algún contexto y admita dos o más interpretaciones antagónicas ${ }^{18}$. Si tomamos de nuevo el ejemplo de aderezar del $D H$, comprobaremos que muchas de sus acepciones no se oponen entre sí. Ya he señalado el problema de la separación entre los complementos de objeto en casos como II.7 y II.8. Es evidente que, semánticamente, nos hallamos ante el mismo sentido:

7. tr. Adornar, decorar, amueblar un aposento, una casa, una calle o un lugar en general. Ú.t.c.prnl. y en sent.fig.

Aderezaron muy bien la dicha yglesia [...]

8. tr. Adornar, decorar un objeto.

[...] e le llevantaron de ahí el asiento real, el cual estaba muit aderezado

17 Los conceptos abarcados por las formas lingüísticas no son los mismos en todas las lenguas. En islandés, por ejemplo, encontramos palabras diferentes que designan realidades representadas siempre de modo aislado en otras lenguas; existen vocablos para designar conjuntamente al padre y al hijo (o hijos varones), al padre y la hija (o hijas), frente a la madre y la hija (o hijas) y la madre y el hijo (o hijos varones): así, padre se dice fadir, padre e hijo (o hijos), fedgar, padre e hija (o hijas), fedgin, etc. Esta idea, de clara raíz estructuralista, es aceptada hoy día por un gran número de semantistas. Cruse también menciona, a este respecto, los casos de hand (en inglés) y xeri (en griego): mientras hand sirve para denominar la mano hasta la muñeca, xeri incluye la muñeca y llega hasta el codo (Cruse 2004: 182).

18 Sigo a Cruse 2004: 105 y ss. 
La prueba es que en un contexto de zeugma como "Aderezaron el palacio, el asiento real y el cetro" no se plantean dos o más lecturas antagónicas que entren en conflicto semántico y la oración habría sido, en la Edad Media y salvando las distancias fonéticas, perfectamente posible $^{19}$. Esta clasificación del $D H$ carece, por tanto, de relevancia lexicográfica y es aplicable, por las mismas razones al caso de las subacepciones. La acepción número 12 se reduciría notablemente si prescindiéramos de los grupos de sustantivos que se combinan con aderezar con el sentido único de "reparar". Se podría decir, por el contrario, que los sustantivos con los que frecuentemente se combina son armas, embarcaciones, puentes...

Un diccionario histórico debería buscar la economía en la clasificación, centrándose en la relación entre las palabras y los conceptos más que en la presentación ordenada de las ocurrencias de un corpus, por grande y completo que sea.

\section{INTENTO DE DEFINICIÓN DE ADEREZAR EN EL DH}

Sin pretensión de dar una única solución al problema, me despreocuparé un poco de la minuciosidad filológica al definir el vocablo aderezar, prefiriendo ganar en coherencia desde el punto de vista de la semántica. Me permito, también, hacer algunas correcciones en la interpretación y presentación de los ejemplos cuando me parece significativo e intuyo con una cierta claridad que no corresponden a la definición dada por el $D H$. Claro está que, consciente de mis limitaciones a este respecto, las propuestas han de quedar abiertas a la discusión.

La entrada, como ya he tenido ocasión de señalar más arriba, podría dividirse en dos ramas muy precisas que se desprenden del propio origen etimológico:

I. Idea general de dirigir, conducir.

II. Idea de general de disponer adecuadamente.

19 Criterio tomado de Cruse (2004: 106), para quien resulta fundamental. Porto Dapena (2002: 214-215), basándose en Melčuk, lo denomina "criterio de coocurrencia compatible". 
La primera de las ramas semánticas ha sido especialmente productiva, tanto en la Edad Media como en la Edad Moderna y genera acepciones relacionadas con la idea física o metafórica de camino (conducir o llevar por el buen camino). Gracias a la sintaxis, descubrimos un sentido de desplazamiento físico, un equivalente del verbo "dirigirse [a un lugar]" que se caracteriza por su intransitividad y por su preferencia por complementos locativos. Los ejemplos nos muestran que se utiliza la preposición $a$ o en, e incluso ninguna, si estimamos que el ejemplo de 1250 recogido en la acepción número 1 del $D H$ cabría incluirlo en este grupo $^{20}$.

1. Dirigirse, encaminarse [a un lugar determinado] [por un sitio determinado].

Aparece muy temprano la idea de guiar o conducir. Metafóricamente primero, referido a personas (guiar moralmente) o a estados (poner en orden, gobernar). Se trata, esta vez, de estructuras transitivas:

2. Dirigir, guiar moralmente, aconsejar.

3. Dirigir, ordenar, administrar, gobernar.

Con el sentido transitivo de "dirigir, conducir" fisicamente aparece más tarde. Naturalmente, lo que para el $D H$ actual es una subacepción del punto 4, debería considerarse una acepción. Los ejemplos pertenecientes a la definición "dirigir el camino o marcha" (número 4 en el $D H)$ plantean problemas particulares que trataré más adelante.

4. Dirigir, conducir [a una persona, cosa] [a un lugar determinado]

La subacepción c) del punto 4 no es más que una nueva acepción destacada también por la sintaxis:

5. Dirigir, apuntar [algo] [hacia un lugar] [en una dirección]

La acepción recogida como punto 5 por el $D H$ constituye, verdaderamente, una acepción aislada que se refleja, no sólo en su significado, sino también en su estructura sintáctica (aderezar [algo] a [alguien] [al-

20 "E adelanta con que adereces el otro mundo, e aderesçarse ha el fecho de este mundo". Veo difícil aquí interpretar el verbo como "dirigir moralmente". Este ejemplo plantea problemas que habría que tratar filológicamente. 
gún lugar]). Se trata de un sentido extraño -'enviar', 'dirigir'-, emparentado con otros romances como adresser (fr.) o adresar (cat.). El nuevo sentido se introduce en el s. XV y se agota, en principio, muy pronto, pues no tenemos más ejemplos a partir de 1463. Sin entrar ahora en la discusión de si se trata de un préstamo efímero, parece evidente que habría que situarla a continuación, independientemente:

6. tr. Dirigir, enviar, dedicar (palabras, cartas, escritos, etc.).

La segunda de las líneas semánticas resulta mucho más compleja porque incluye las restantes ramas del $D H$. Hay un sentido genérico de 'disponer adecuadamente', 'rectamente', si se prefiere; es decir, la intención de intervenir para lograr que algo se adapte a una determinada regla. No es de extrañar que todas las acepciones se caractericen por su transitividad. Estas acepciones serían las siguientes:

7. Componer, asear, adornar [a alguien] [algo] [de, con algo]

Ésta incluiría las antiguas 6, 7, 8, 9 y 10, y 11 aunque tal vez admitiría una división en tres subacepciones:

7. Componer, asear, adornar [a alguien] [algo]

7.a) Componerse, asearse, embellecerse [de, con algo]

7.b) Componer, asear, embellecer [a alguien] [algo] [de, con algo]

7.c) Acompañar, completar [una acción, una obra, etc] [con algo]

Una octava acepción tendría en cuenta el sentido de 'reparar' e incluiría la duodécima y decimosexta acepciones del actual $D H$, simplificadas desde el punto de vista de las subacepciones:

8. Reparar [algo]

8.a) Arreglar [una cosa, preferentemente armas, embarcaciones y casas]

8.b) Arreglar, recomponer [un texto, relato, etc]

Las acepciones 13,14 , y 15 quedarían también como acepciones independientes.

9. Enmendar, corregir moralmente.

10. Enderezar poner derecha [una cosa]

11. Curar los trastornos y dolencias.

Otra de las grandes acepciones, que reagrupa varias de las antiguas 
$(17,18,19,20,21,22,23,26$ y 27) haría referencia a los conceptos de 'preparar' o 'disponer':

12. Preparar, disponer [todo tipo de cosas; aparecen principalmente en el corpus: comida, bebida, objetos (armas, mesa, carros, cama, tejidos, etc.), lugares y cosas abstractas y acciones] [animales] [personas] [para algo, raramente de algo]

Precisamente, el hecho de que aparezca este gran sentido de 'preparar' pone de manifiesto un aspecto importantísimo del verbo adere$z a r$ en relación con la situación lingüística actual. Resulta curioso comprobar que una palabra de tanto uso hoy en día como preparar se haya introducido tardíamente en español -concretamente en el XVII, o finales del XVI como muy temprano- y haya ido ganando terreno poco a poco hasta apoderarse de esta acepción, hoy desaparecida casi por completo. Y digo "casi por completo" porque, a pesar de todo, nos quedan algunos restos, curiosamente en ámbitos especialmente conservadores, como la cocina. Hoy sólo decimos aderezar la ensalada o aderezar la carne (cada vez menos), y ello en convivencia con la más neutra preparar la ensalada o preparar la carne (condimentarla). Es más, preparar alterna con otro verbo mucho más tardío: arreglar (s. XVIII), que también ha invadido el área conceptual reservada a aderezar.

Haciendo un pequeño estudio analógico para el resto de las acepciones, nos daremos cuenta de que aderezar aparecía como el vocablo no marcado para referirse a algunos conceptos de gran importancia: la orientación en el espacio, concepto que fue tomando el verbo dirigir a partir del siglo XV, momento en que se rastrea por primera vez; el aseo personal, para el que con carácter arcaizante pueden aún encontrarse ejemplos con aderezar, pero que ha sido abandonado, precisamente, en favor de preparar(se), arreglar(se), etc.; el sentido de "reparar", también perdido frente a arreglar; y el caso ya señalado de preparar. Los verbos que ahora usamos con tanta naturalidad irrumpían en el sistema lingüístico con la fuerza del neologismo desestabilizador. Parece evidente que los cambios experimentados por aderezar no pueden entenderse al margen de la potenciación de los verbos que fagocitaron su esfera conceptual. Por eso es fundamental llevar a cabo 
una descripción de las entradas desde un punto de vista relacional. Del mismo modo que se ha definido este vocablo habría que definir los vocablos que entran en contacto con él y provocan la reestructuración del sistema. Más que una clasificación minuciosa de todas las ocurrencias ofrecidas por el corpus, el establecimiento adecuado de las grandes acepciones nos da una perspectiva más clara de los grandes cambios semánticos.

Para terminar, hay que señalar que tras esta duodécima acepción, aparecerían aún tres independientes, dos de las cuales son tardías:

13. Presentarse [a alguien] [una contingencia]

14. Colocar, acomodar, adaptar [algo] [a algo]

15. Cubrir [el macho] [a la hembra] (dialectal)

Por supuesto, no se podría olvidar un apartado dedicado a la fraseología y otro dedicado a los ejemplos problemáticos del corpus que merecería un tratamiento especial. Dichos apartados no serían ni ramas semánticas ni acepciones o subacepciones. En el apartado de fraseología aparecería la rama VI del $D H$ y entre las cuestiones problemáticas habría que citar las planteadas por la actual acepción 4, cuyos ejemplos, a mi entender, parecen orientarse más hacia la lexicalización.

\section{APÉNDICE 1.}

Esquema del nuevo artículo aderezar en el Diccionario Histórico.

\section{aderezar.}

I. Con idea de dirigir, llevar a algún sitio, conducir.

1. intr. Dirigirse, encaminarse [(a o en) un lugar determinado] [por un sitio determinado].

Los primeros ejemplos se sitúan cronológicamente a mediados del S. XIII. La acepción desaparece muy pronto (S. XVI) sin dejar huella en la lengua actual.

2. tr. Dirigir, guiar moralmente.

Esta acepción tiene también un origen temprano. Su apogeo se sitúa entre los siglos XIII Y XV; a partir del S. XVI desparece sin dejar rastro.

3. tr. Dirigir, ordenar, administrar, gobernar.

Como las anteriores, se mantiene en vigor hasta el S. XVI, aunque es posible encontrar ejemplos de regusto arcaizante hasta la primera mitad del $S$. XX. 
4. tr. Dirigir, conducir [a una persona, cosa] [a un lugar determinado].

Ss. XIII-XVI. A partir de esta fecha no vuelve a presentarse en los textos.

5. tr. Dirigir [algo] [hacia un lugar] [en una dirección], apuntar.

Ss. XIII-XVI. No vuelven a encontrarse ejemplos a partir de esta fecha.

6. tr. Dirigir, enviar, dedicar (palabras, cartas, escritos, etc.) Ú. t. c. prnl.

Acepción de origen incierto (probablemente francés o catalán), atestiguada por primera vez en el $S$. XV y desaparecida poco después sin dejar rastro.

II. Con idea de disponer adecuadamente.

7. Componer, asear, adornar [a alguien] [algo].

Aderezar, en esta acepción, aunque no ha desaparecido por completo, ha sido sustituido progresivamente por otros verbos, como "arreglar(se)" o "preparar(se)".

7.a) Componerse, asearse, embellecerse [de, con algo].

Este sentido aparece ya en textos del S. XIII y se mantiene hasta la actualidad, aunque, hoy en día, su uso contiene un cierto gusto arcaizante.

7.b) Componer, asear, embellecer [a alguien] [algo] [de, con algo].

Con complemento humano, por analogía con 7.a) sigue usándose en la lengua actual. Con objetos ha desaparecido completamente o aparece, con muy poca frecuencia, como arcaísmo evidente en textos literarios.

7.c) Acompañar, completar [una acción, una obra, etc] [con algo]. Atestiguado desde el S. XVII, se conserva hasta la actualidad, aunque hoy sólo se utiliza con el sentido más restringido de "hacer más amena una exposición añadiendo observaciones graciosas".

8. Reparar [algo].

8.a) Arreglar [una cosa, preferentemente armas, embarcaciones y casas].

Su origen se remonta al $S$. XIII y puede considerarse desaparecido del sistema lingüístico a partir entre los Ss. XVI-XVII. Todavía podía encontrarse como arcaísmo en los Ss. XVIII-XIX.

8.b) Arreglar, recomponer [un texto, relato, etc].

Este sentido se fecha por primera vez en el $S$. XVII y produce ejem-

plos, aunque no muy numerosos, hasta principios del S. XX.

9. Enmendar, corregir moralmente.

Se extiende desde el S. XIV al S. XVI, momento en que desaparece definitivamente.

10. Enderezar poner derecha [una cosa].

Originado también en el S. XIV se mantiene vigente, al menos, hasta el S. XVIII, momento en que empieza a ser considerado un arcaísmo evidente.

11. Curar [trastornos y dolencias].

Ss. XV-XVII, fecha en que desaparece definitivamente. 
12. Preparar, disponer [todo tipo de cosas; aparecen principalmente en el corpus: comida, bebida, objetos (armas, mesa, carros, cama, tejidos, etc.), lugares y cosas abstractas y acciones] [animales] [personas] [para algo, raramente de algo].

Los primeros ejemplos aparecen en el $S$. XIII. Su uso empieza a decaer a partir del $S$. XVII y desaparecen definitivamente a finales del S. XIX o principios del S. XX, cuando todavia podía usarse como arcaísmo. Se han conservado en la lengua actual, fosilizadas, algunas combinaciones en el ámbito de la cocina con el sentido particular de condimentar (aderezar la ensalada y aderezar la carne), si bien compite con otros verbos que han ido desplazando a "aderezar" en el significado general de "preparar, disponer", como "arreglar" o el mismo "preparar".

13. Presentarse [a alguien] [una contingencia].

Ss. XIII-XVII.

14. Colocar, acomodar, adaptar [algo] [a algo].

Significado atestiguado en el s. XV y desaparecido entre los SS. XVIII y XIX.

15. Cubrir [el macho] [a la hembra] (dialectal).

Significado creado a mediados del s. XX con carácter dialectal. Se usa preferentemente en Alava y Navarra.

Fraseología.

Problemas del corpus. 
APÉNDICE 2.

Presentación en forma de gráfico del artículo aderezar del Diccionario Histórico.

I. Dirigir, conducir

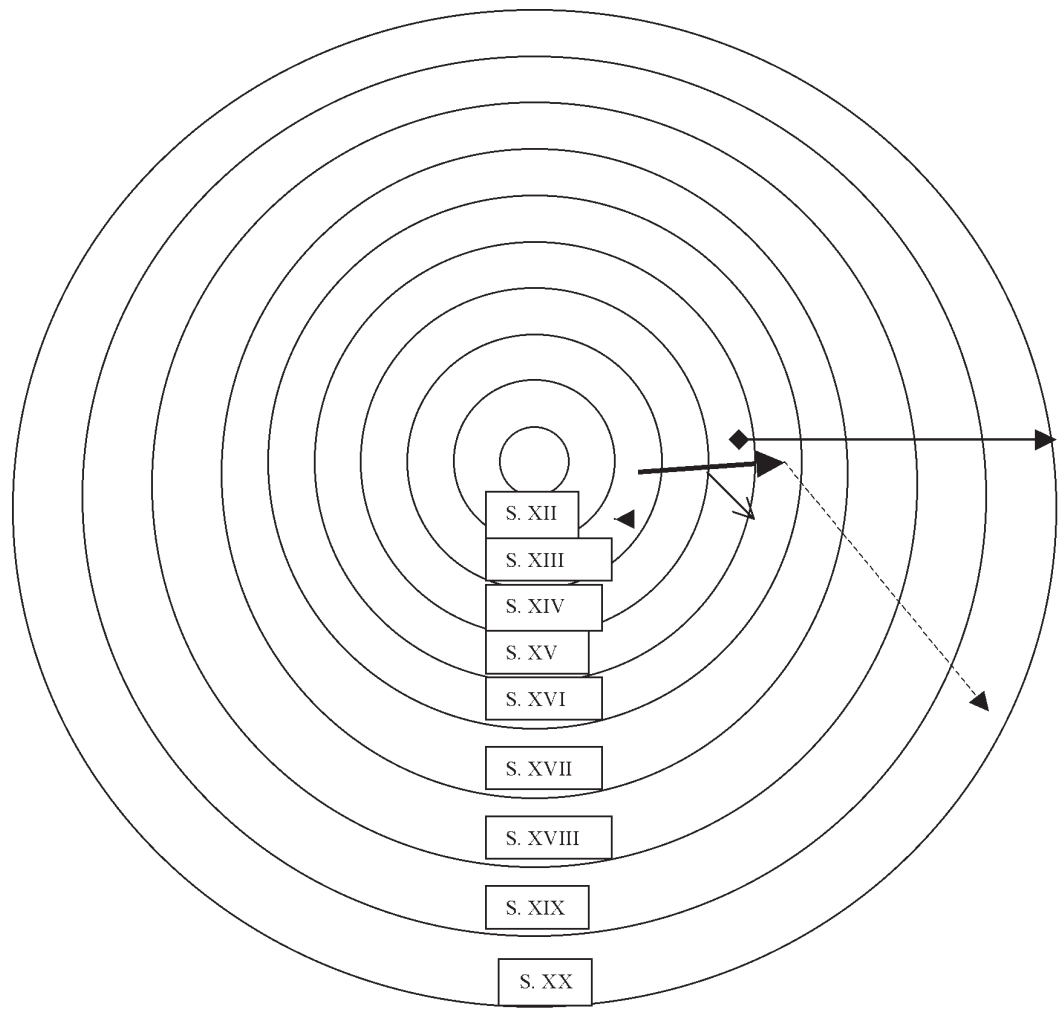

$\longrightarrow \quad$ Uso vivo de las acepciones $1,2,3,4$ y 5 de aderezar

Prolongación como arcaísmo de la acepción 3 de aderezar

$\longrightarrow \quad$ Acepción 6 de aderezar como excepción semántica y sintáctica. Probablemente

$\longrightarrow$ Verbos dirigir (en su forma pronominal y transitiva) y conducir. 


\section{Disponer adecuadamente.}

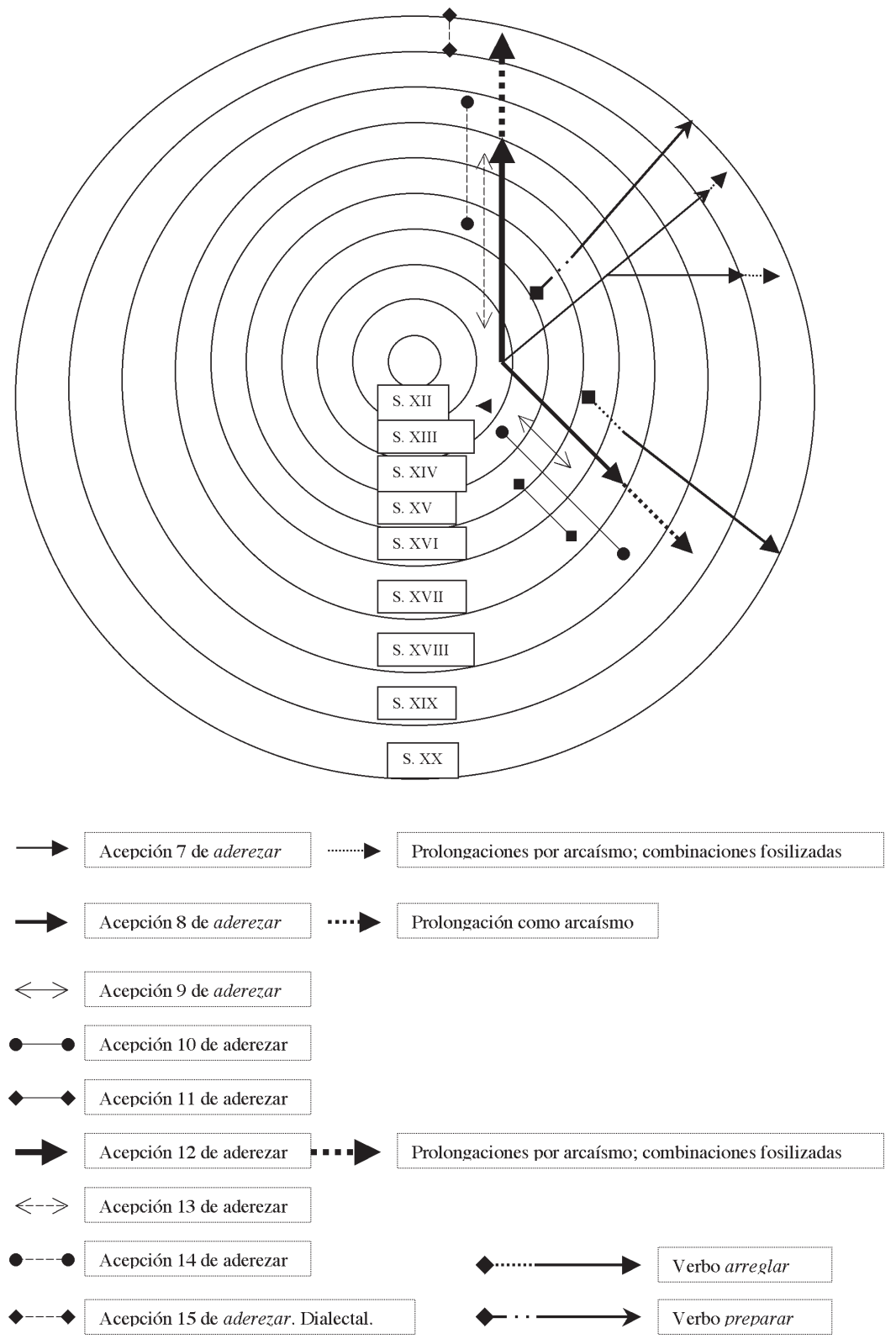


BIBLIOGRAFÍA

CASARES, J. (1992): Introducción a la lexicografía moderna, Madrid, CSIC.

Corominas, J. y J. A. PAscual (1980-1991): Diccionario crítico etimológico castellano e hispánico, Madrid, Gredos.

Cruse, A. (2004): Meaning in language. An Introduction to Semantics and Pragmantics, Oxford, Oxford University Press.

PAscual, J. A. y R. GARcía PÉrez (en prensa): "Las relaciones entre las palabras en un diccionario histórico: la relación genética".

Porto DAPENA, J.-A. (2002): Manual de técnica lexicográfica, Madrid, Arco/Libros.

Real ACAdemia Española (1972): Diccionario histórico de la lengua española, Madrid, Espasa-Calpe.

SECo, M. (1987): Estudios de lexicografia española, Madrid, Paraninfo. 